\title{
EFFECT OF BLACK CARBON ON THE GROWTH, DEVELOPMENT AND EVAPOTRANSPIRATION OF MAIZE
}

\author{
ANDA, A. ${ }^{1} *-$ JAKUSCH, P. ${ }^{1}-$ KoCSIS, ${ }^{1}{ }^{1}$ \\ ${ }^{1}$ University of Pannonia Georgikon Faculty \\ P. O. Box 71. Keszthely, Hungary H-8361 \\ (Tel: +36-83-545-149; +36-30-641-8598) \\ *Corresponding author \\ e-mail:anda-a@georgikon.hu, jakusch.pal@gmail.com; timea.kocsis@gmail.com \\ (Received $9^{\text {th }}$ August 2011; accepted $2^{\text {nd }}$ September 2013)
}

\begin{abstract}
The effect of soot on certain parameters of maize was analysed. We applied low rates of soot (3 $\mathrm{gm}^{-2} \mathrm{week}^{-1}$ ) with a motorised sprayer. The effect of soot on evapotranspiration was tested on plants grown in evapotranspirometer (ET). Soot pollution had no influence on maize growth and development. Leaf withering after full maturity, however, was delayed by the presence of soot. The ability of soot to absorb irradiation and thus increase leaf surface temperatures led to an increase of $4 \%$ in the annual evapotranspiration sum. Soot pollution reduced dry matter (DM) on the rainfed plots $(8.8 \%)$, but not in the ET tanks. In the ET tanks, soot had no significant influence on either the stalk or the grain DM, though slight reductions were recorded. On the non-irrigated plot there was $12.4 \%$ reduction in grain dry matter in response to pollution. Supplementary water supplies mitigated the plant damage caused by soot. A further advantage was detected in the number of deformed ears.
\end{abstract}

Keywords: soot (black carbon), maize, evapotranspiration, yield

\section{Introduction}

Black carbon (BC), also referred to as elemental carbon, is most often released through the incomplete combustion of fossil fuels, the burning of biomass or as diesel exhaust. It consists of highly condensed carbonaceous by-products (e.g. soot) and residues (e.g. charcoal) (Schmidt and Noack, 2000; Agarwal and Bucheli, 2011). Uncertainties are caused by the use of BC as a generic term for a broad continuum of condensed and carbonised products, ranging from slightly charred materials to graphitic soot (Qénéa et al., 2006). There are also discrepancies in the methods used to detect the components of BC and even in the quantitative data (Schmidt et al., 2001).

As the main constituent of soot, it is $\mathrm{BC}$ that is almost exclusively responsible for light absorption by particles in the atmosphere (Taha et al., 2007), thus changing the radiation balance of the Earth and contributing to global warming. The last report from IPCC (2007) gave a consensus estimate of the warming influence of BC as $0.34 \pm 0.25$ $\mathrm{W} \mathrm{\textrm {m } ^ { - 2 }}$, but Ramanathan and Carmichael (2008) used data from satellites, aircraft and surface instruments to calculate that the warming effect of $\mathrm{BC}$ in the atmosphere is three to four times greater than this (averaging approx. $0.9 \mathrm{~W} \mathrm{~m}^{-2}$, with a range of 0.4-1.2 $\mathrm{W}$ $\mathrm{m}^{-2}$ ). According to Samaras and Meisterling (2008) road transport alone accounts for a warming effect of $0.18 \mathrm{~W} \mathrm{~m}^{-2}$, while Borken et al. (2007) calculated that in 2000 the global particulate matter (PM) emission from road transport was $1.37 \mathrm{Tg}$, half of which $(0.72 \mathrm{Tg})$ consisted of BC. Current estimates of global BC formation range from 44-194 Tg a year (Kuhlbusch and Crutzen, 1996).

Many factors, such as the type of chemical constituents in the particles, the range of particle size and the diversity of crop canopy structures, have slowed progress in studies 
on the impact of PM on vegetation, and hardly any information is available on the effect of $\mathrm{BC}$, a contributor to human health hazards, on crops. The regulatory size classes established for medical purposes have little relevance to vegetation, and even the deposition of BC on vegetation is still poorly understood (Smith and Jones, 2000).

Studies on the direct effects of particles on crops have not yet reached the stage of reproducible exposure experiments (Grantz et al., 2003), being complicated by the lack of experimental techniques for applying ambient particles to vegetation.

The deposition of PM on the foliage surface has a direct effect, but there is also an indirect effect through alterations in the soil nutrient cycle. Pietikäinen et al. (2000) and Steiner et al. (2004) found that BC promotes the growth and activity of microorganisms in the soil, though it is still not clear whether the presence of $\mathrm{BC}$ leads to the accelerated mineralization of plant litter in the presence of soil minerals (Lehmann and Sohi, 2008). It was concluded by Liang et al. (2010) that knowledge on the role of BC in the global $\mathrm{C}$ cycle should be expanded to include the soil, as indirect effects may be the most significant in the case of vegetation (Grantz et al., 2003).

$\mathrm{BC}$ is a component of the natural environment, and may have a complex effect in nature. Due to its high radiation absorption ability, it may contribute to global warming. The results achieved by many scientists in this field were summarised in the Fourth IPCC Assessment Report. Much work has also been carried out on the impact on the soil of the soot arising as a by-product of biomass combustion (Lorenz et al., 2010). Although the atmospheric pollutants reaching the soil first have to pass through the crop canopy, few investigations have been made on the effect of $\mathrm{BC}$ on vegetation. The present study therefore addressed the impact of $\mathrm{BC}$ on the growth, development and evapotranspiration of field-grown maize, using a reproducible contamination method. The BC used by the Hungarian representative of the Hankook tyre factory to increase the wear resistance of tyres was used as pollutant. As the aim of the research was to simulate pollution arising from road transport, low rates of pollution were applied, but these were repeated at weekly intervals. The effect of road transport on the environment, including the responses of crops, is likely to gain greater importance in the near future.

\section{Materials and methods}

The impact of black carbon on the growth, development and evapotranspiration of maize grown at various water supply levels was studied at the Agro-meteorological Research Station in Keszthely, Hungary during the 2010 growing season. A Swiss-bred maize hybrid, Sperlona (FAO 340), with a short vegetation period, was sown in the experiments at the plant density (70,000 plants per hectare) widely used under Hungarian climatic conditions for growing grain maize.

The soil was Ramann's brown forest soil with a mean bulk density of $1.46 \mathrm{Mg} \mathrm{m}^{-3}$ in the top $1 \mathrm{~m}$ of the profile and an available water capacity of $150 \mathrm{~mm} \mathrm{~m}^{-1}$. Nutrients (180, 80 and $120 \mathrm{~kg} \mathrm{ha}^{-1} \mathrm{~N}, \mathrm{P}$ and $\mathrm{K}$, respectively) were applied in spring, immediately prior to sowing. The usual agronomic measures (plant protection, weed control) recommended for the location by the staff of the University of Agricultural Sciences, Keszthely, were applied. 
The phenological phases observed are given below together with their $\mathrm{BBCH}$ codes:

Growth stage

Emergence

Tasselling (anthesis)

Milky ripeness

Dough stage

Fully ripe

Plant dead
Description

First leaf unfolded

Upper and lower parts of tassel in flower

Kernels in middle of cob yellowish-white, content milky, about $40 \%$ DM

Kernels yellow, about 55\% DM

Kernels hard and shiny, about 65\% DM

No green leaves, plants collapsing
Code

11

65

75

85

89

99

Of the two water supply treatments, the rainfed variant was sown in field plots, while compensation evapotranspirometers of the Thornthwaite type were used for the ad libitum treatment. These were metal containers (ET chambers) with a volume of $4 \mathrm{~m}^{3}$ $(2 \times 2 \mathrm{~m}$ in area, $1 \mathrm{~m}$ in depth), filled with a monolith from the surrounding field, layered as in the natural state. The working principle was to record the components of the water balance each day, expressing evapotranspiration as the residual term. To minimise soil water and canopy differences, the area surrounding the ET was irrigated. Due to the fixed nature of evapotranspirometers, the experiment was laid out in a block design with four replications, while the dry plots were arranged in a randomised complete block design with five replications. The plots had the same area $\left(4 \mathrm{~m}^{2}\right)$ as the evapotranspirometers. The treatment codes used in the experiment were as follows:

Treatment

Water supplies:

Rainfed plots

Evapotranspirometer chamber

Contamination levels

No pollution (control)

Crop pollution with $\mathrm{BC}$

\section{$\underline{\text { Code }}$}

$\mathrm{P}$

ET

$\mathrm{C}$

$\mathrm{BC}$

The BC used by the Hankook Tyre Company (Dunaújváros, Hungary) to improve the wear resistance of tyres was used as pollutant (Fig. 1). This pollutant enters the atmosphere directly during vehicle transport. The size distribution is characterised by $10 \%$ below $3.13 \mu \mathrm{m}, 50 \%$ below $18.8 \mu \mathrm{m}$ and $90 \%$ of the total soot quantity below 50.6 $\mu \mathrm{m}$. The pollutant is chemically "pure", i.e. it is free of other contaminants, such as heavy metals, so the reproducibility of the experiment is not problematic, unlike that of tests on other air pollutants. Relatively small doses were applied $\left(3 \mathrm{~g} \mathrm{~m}^{-2}\right)$, repeated at weekly intervals. A motorised sprayer (SP 415) was used to apply the pollutant. 


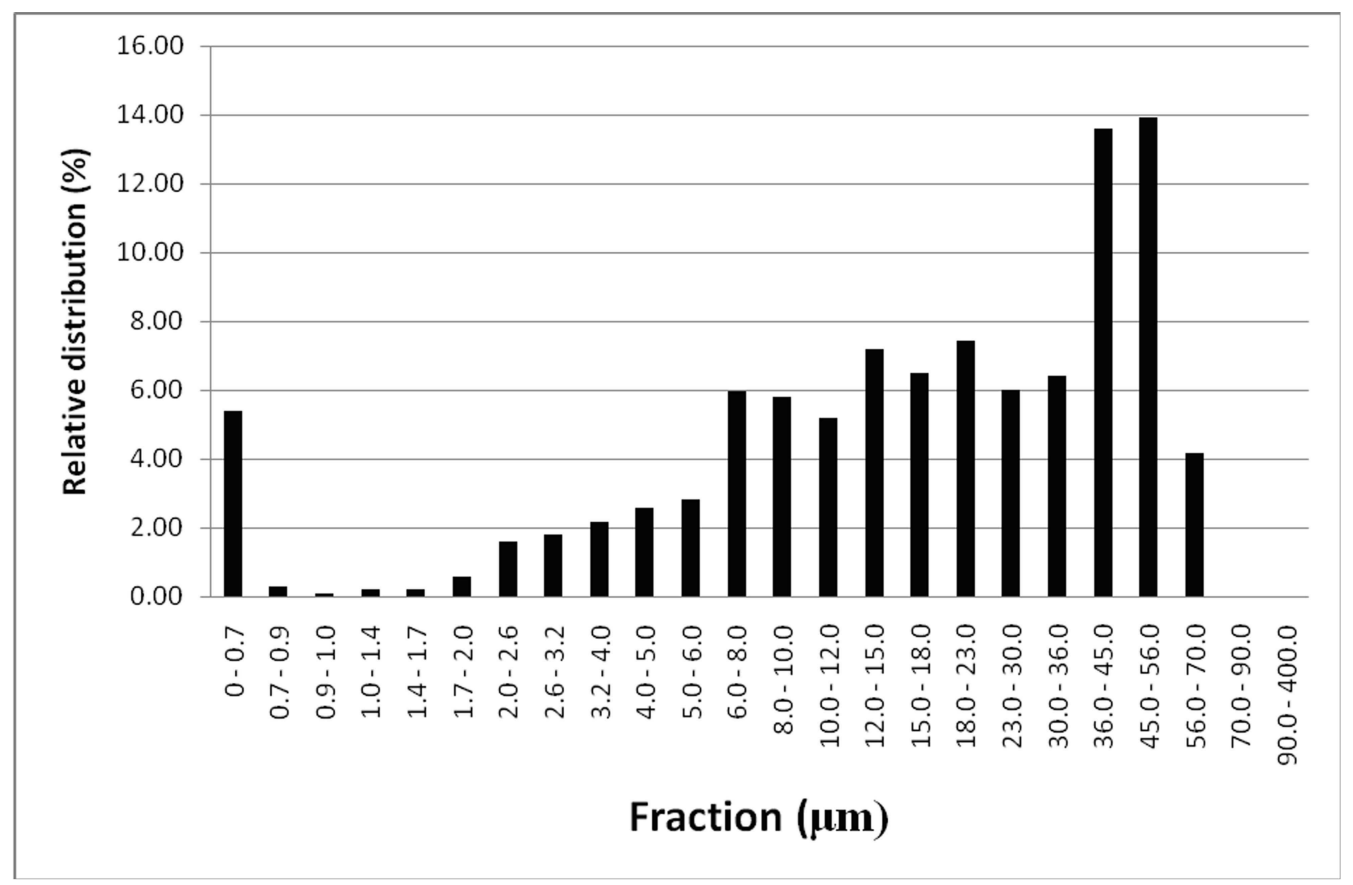

Figure 1. Percentage distribution of the BC fractions applied

The leaf area index was measured each week on the same 12 sample plants in each treatment using an LI 3000A automatic planimeter (LI-COR, Lincoln, NE).

After canopy closure the crop surface temperature was sensed remotely between 12 and $14 \mathrm{pm}$ on cloudless days using an infrared thermomenter (RAYNGER II model, Raytek, Santa Cruz, CA) with an optic angle of $8^{\circ}$ and a spectral range of 8-12 $\mu \mathrm{m}$. The instrument was held $1 \mathrm{~m}$ above the canopy at an angle of $30^{\circ}$ below the horizontal. Approximately 25 temperature readings, measured every $2 \mathrm{~s}$, were averaged for each measurement, and this was repeated three to five times. The emissivity was assumed to be 0.98 .

At the end of the season, the dry matter (DM) contents of the plants (stalk and grain separately) were determined after drying to constant weight at $60^{\circ} \mathrm{C}$. The harvest index was computed as the ratio of the grain to the aboveground dry matter at harvest.

Data analysis was performed using the STATA 5.0 computer package (Stata Corporation, 1997). The t-test was used to determine significant differences between the dry matter yields of polluted and control plants and of rainfed and ET-grown plants.

The meteorological data were obtained from the local QLC-50 automatic weather station.

\section{Results and Discussion}

\section{Weather extremes in the 2010 growing season}

The meteorological data for growing seasons (April to August) during the period 1901-2000, obtained from the Keszthely meteorological station, were used as climate norms in the comparison. Monthly mean air temperatures and precipitation sums were compared to the monthly data of the 2010 growing season. 
Extremely high rainfall sums amounting to more than twice the average figures (242\%, 249\% and 230\%) were observed in May, August and September, respectively (Fig. 2).

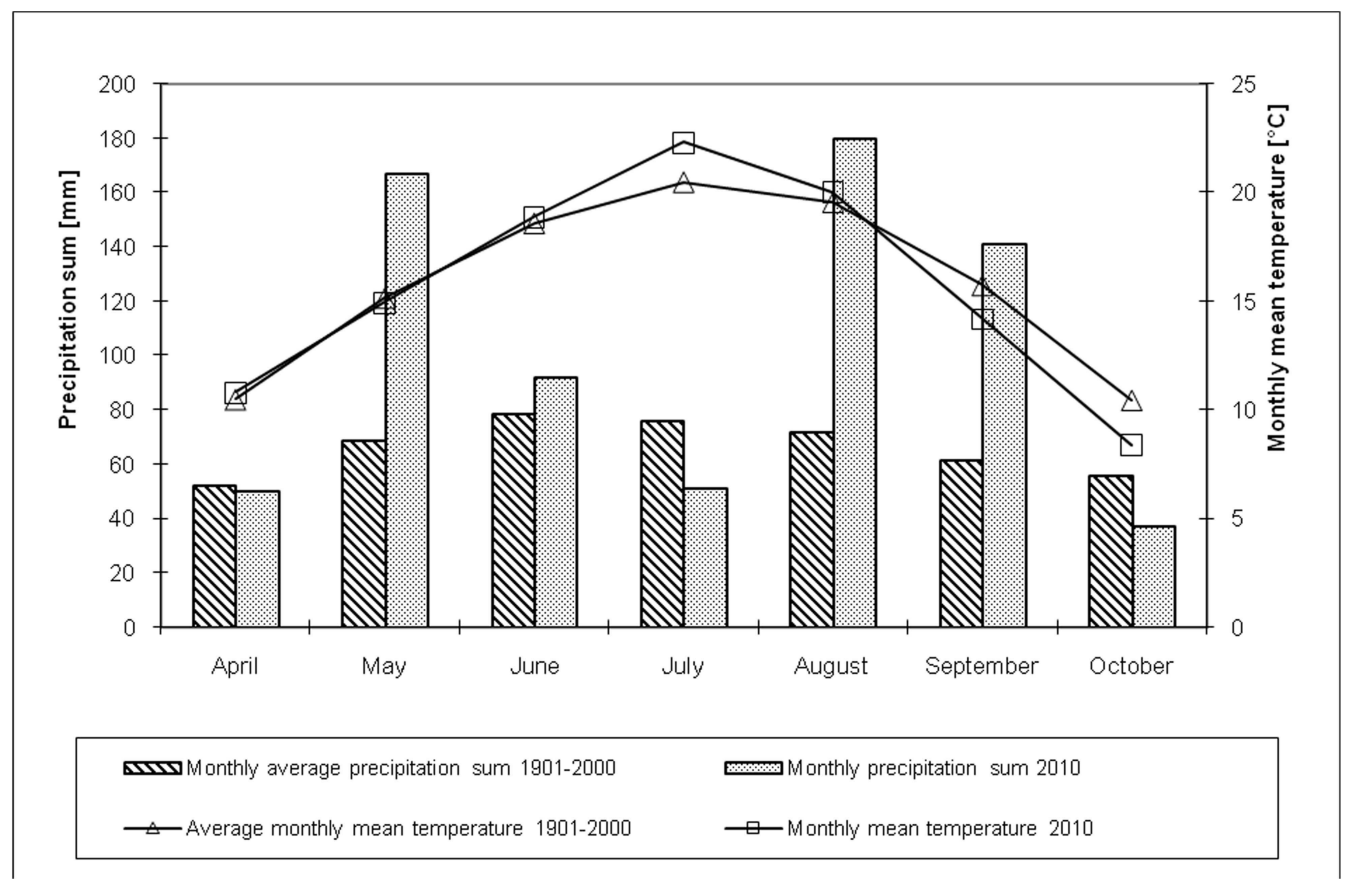

Figure 2. The meteorological elements in 2010 and the climatic norms. The first graph stands for monthly air temperatures, and the second one for precipitation sums

Somewhat higher precipitation than average $(117 \%)$ was also recorded in June. In April, July and October, however, the monthly rainfall sums were below the mean figures for the 1901-2000 period. All in all, the growing season in 2010 was thus far wetter than the long-term mean.

With the exception of three months, the monthly mean temperatures were in good correspondence with the long-term mean. In July the mean temperature was $1.8{ }^{\circ} \mathrm{C}$ higher than the 1901-2000 mean, while the mean temperatures in September and October were below average $\left(-1.5^{\circ} \mathrm{C}\right.$ and $-2^{\circ} \mathrm{C}$, respectively).

\section{Maize development; length of the growing season}

The moderately warm weather in spring and the double quantity of rainfall in May were favourable for the initial development of the maize crop, and there were no differences between the two treatments (rainfed and irrigated) in the length of the phenological phases or the date at which they occurred (Table 1). 
Table 1. Development of maize during the 2010 growing season. The date of canopy closure was important for the measurement of surface temperature, and the date of drying down for analysing the effect of soot

\begin{tabular}{c|c|c|c|c}
\hline $\begin{array}{c}\text { Phenological } \\
\text { phase }\end{array}$ & PC & PP & ETC & ETP \\
\hline Sowing & 23 April & 23 April & 23 April & 23 April \\
Emergence & 1 May & 1 May & 1 May & 1 May \\
Canopy closure & 25 June & 25 June & 25 June & 25 June \\
Tasseling & 09 July & 09 July & 16 July & 16 July \\
Milk ripe & 30 July & 30 July & 30 July & 30 July \\
$\begin{array}{c}\text { Dough stage } \\
\text { Fully ripe }\end{array}$ & 19 August & 19 August & 19 August & 19 August \\
$\begin{array}{c}\text { Crop dead } \\
\text { 27 August }\end{array}$ & 27 August & $\mathbf{0 3 ~ S e p t e m b e r ~}$ & $\mathbf{0 3 ~ S e p t e m b e r ~}$ \\
17 September & 17 September & 17 September & $\mathbf{2 3 ~ S e p t e m b e r ~}$ \\
$\begin{array}{c}\text { growing season } \\
\text { (days) }\end{array}$ & $\mathbf{1 2 6}$ & $\mathbf{1 2 6}$ & $\mathbf{1 3 3}$ & $\mathbf{1 3 3}$ \\
\hline
\end{tabular}

Tasseling was the first phenophase where differences occurred, plants in the ET treatment producing tassels a week later in response to additional water supplies. This could probably be attributed to the only "drier" month during the vegetation period: July, when there was 39\% less rainfall than average. Rainfall in all the other months exceeded the 100-year mean. The $180 \mathrm{~mm}$ rain that fell in August was the highest monthly rainfall sum recorded since the data collection was initiated in 1901, and this combined with high air temperature, thus promoting plant development. The dates of milky and waxy ripeness showed no deviation between the two treatments. Due to the above-average rainfall in summer 2010, the short growing period of the FAO 340 maize was slightly protracted. On the control plots full maturity was reached a week earlier than in the ET tanks, i.e. the length of the vegetation period was 7 days shorter for rainfed maize. Earlier observations that supplementary water supplies tended to lengthen the vegetation cycle were thus confirmed even under the extreme rainfall conditions witnessed in 2010.

The effect of soot contamination was not observed until the whole plant had dried down, and then only in the BC-polluted ET treatment, where the contaminated maize retained a few green leaves for a week longer than in the ET control. This effect was not observed on the rainfed plot.

\section{Size of the assimilatory (transpiration) surface}

Air pollution is most closely correlated with the leaf area, because when the leaf area index (LAI) is greater than unity the majority of pollutants settle on aboveground shoots and are only later washed off and reach the ground. The upper layer of foliage is the most exposed part of the plant (Grantz et al., 2003).

During the cool summer of 2010, when precipitation was well above average, there was no significant difference between the mean annual LAI values of non-contaminated maize in the evapotranspirometer and on the rainfed plots. Similar years have only been experienced on one or two occasions in Keszthely over the last thirty years. Soot pollution tended to reduce the mean LAI of rainfed plants by $3.4 \%$ by full maturity (Fig. 3). During the period following full maturity the plants in the polluted treatment dried down more slowly than those in the untreated control. Ripening was recorded in late August and complete drying down took another 2-3 weeks. The descending branch 
of the LAI curve was much steeper for the unpolluted control plants, but the dates of complete drying down were the same. As in the case of the rainfed plots, the mean annual LAI values of maize grown in ET tanks was not significantly modified by BC pollution (Fig. 4).

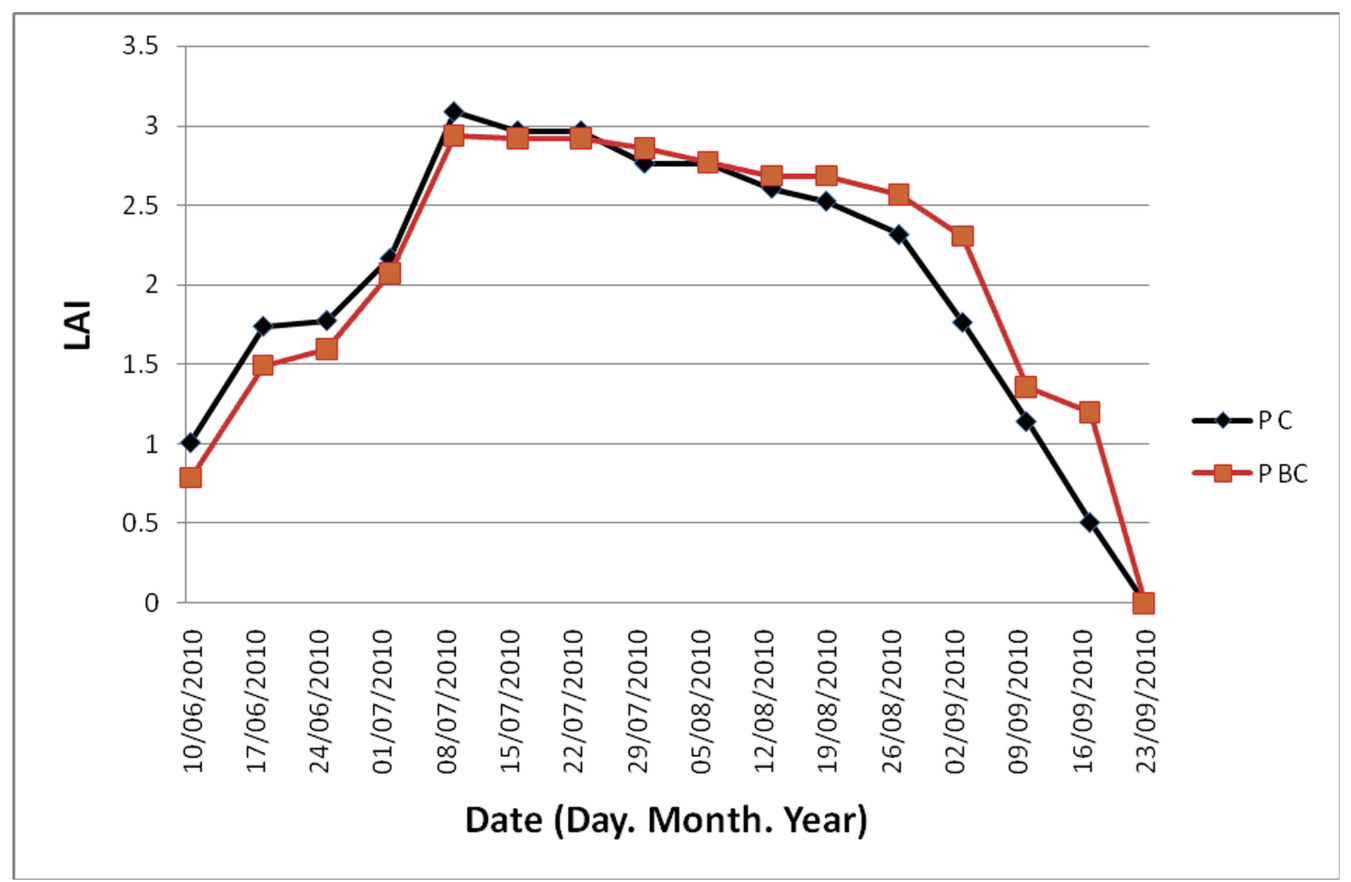

Figure 3. Changes in LAI on non-irrigated plots

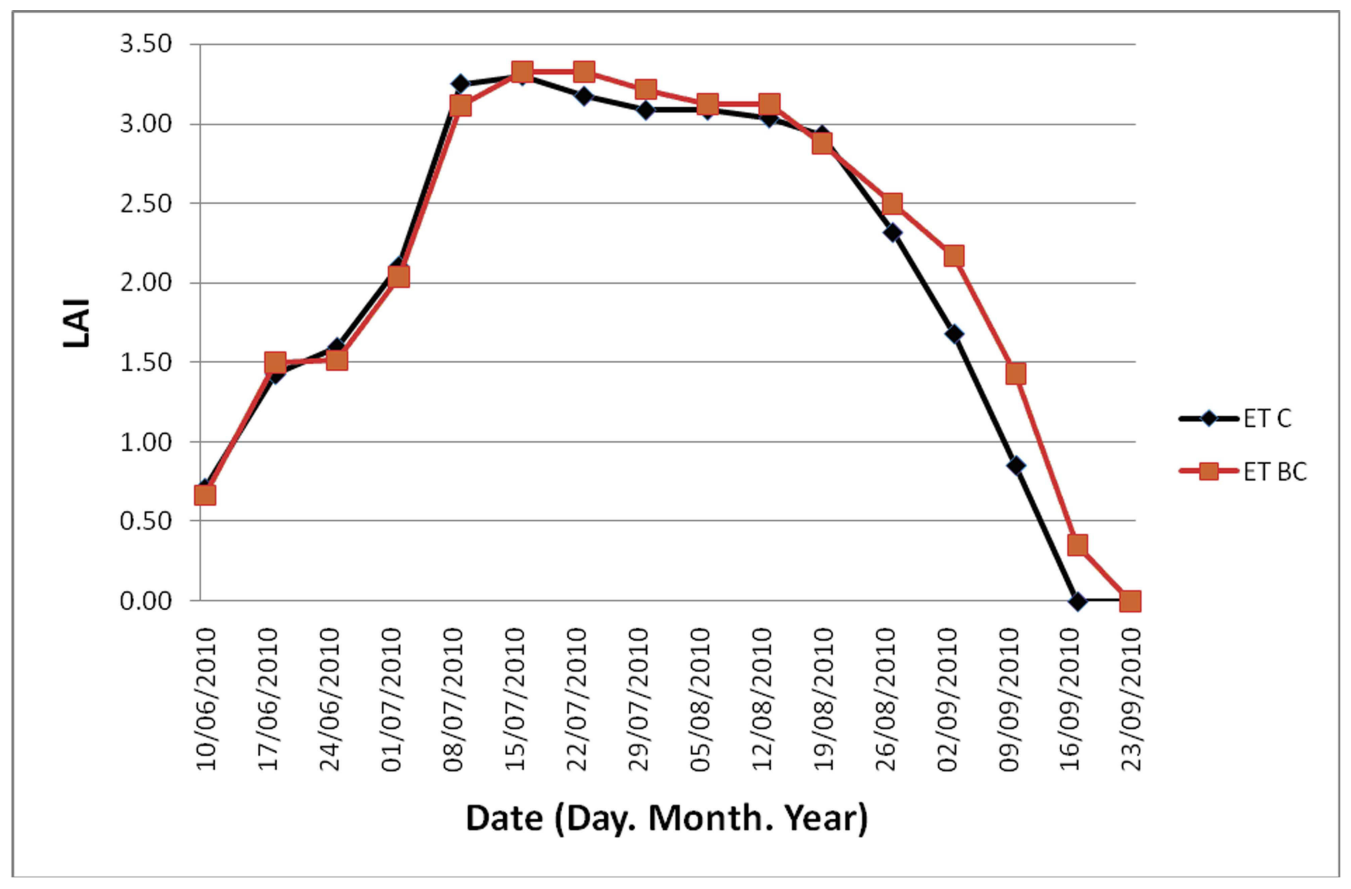

Figure 4. Weekly changes in LAI for ET plants 
The mean LAI during the period from sowing to full maturity was 2.44 and 2.50 in the control and polluted treatments. In the ET tanks, however, greater differences were observed in the rate of drying down after full maturity. Unlike the soot-polluted plants in the rainfed plots, those grown in ET tanks not only stayed green longer, but attained full maturity a week later. (As in the case of rainfed plants, this period was analysed separately, as it had no influence on yield formation, which is the main purpose of maize production.)

In both water supply treatments, differences in drying down after full maturity were observed in September, when the weather was cooler than average $\left(-1.5^{\circ} \mathrm{C}\right)$, combined with double the usual amount of rainfall. It seems that plants adapted to stress in the form of soot pollution were more capable of coping with another form of stress, extreme weather conditions.

Soot pollution did not modify either the maximum value of LAI or the date at which this was observed. The greatest leaf area was recorded a week earlier on non-irrigated plots (both polluted and non-polluted) than in the ET treatment. This corresponds to the delaying effect of additional water supplies on maize development, described above in the discussion of phenophases. In response to pollution the mean annual LAI of plants in the ET treatment was $6 \%$ higher than in the rainfed polluted plots, indicating that even in the wet summer of 2010 irrigation had a positive effect on the leaf area of maize.

\section{Evapotranspiration and crop surface temperature}

The ability of $\mathrm{BC}$ to absorb irradiation was manifested in a rise in plant temperature and in enhanced evapotranspiration. The basic conditions of the paired t-test (normal distribution and similar standard deviations) were fulfilled, so, linear regression was assumed between the two evapotranspirations. Daily change in evapotranspiration was significantly increased by soot pollution, with an increase of $4 \%$ in the annual sum (significant at the $5 \%$ level).

The five-day sums of evapotranspiration, which give a clearer reflection of weather effects (Fig. 5), were more moderate $(6-8 \mathrm{~mm} / 5$-day period) at the beginning and end of the vegetation cycle, when both the leaf area available for evapotranspiration and the solar radiation level were lower. In 2010 the highest evapotranspiration was recorded between $16^{\text {th }}$ and $20^{\text {th }}$ July, when the weather was hotter and drier than average, with a total evapotranspiration of over $30 \mathrm{~mm}$ for the 5-day period. The greatest value of daily evapotranspiration was measured on 23 July $2010(7.7$ and $7.9 \mathrm{~mm}$ in the control and soot-polluted treatment). In both treatments the cumulative evapotranspiration was over $400 \mathrm{~mm}$. This increase could only be partially explained by the hot weather in July. The other reason may have been the protraction of the vegetation cycle due to the excessive rainfall. 


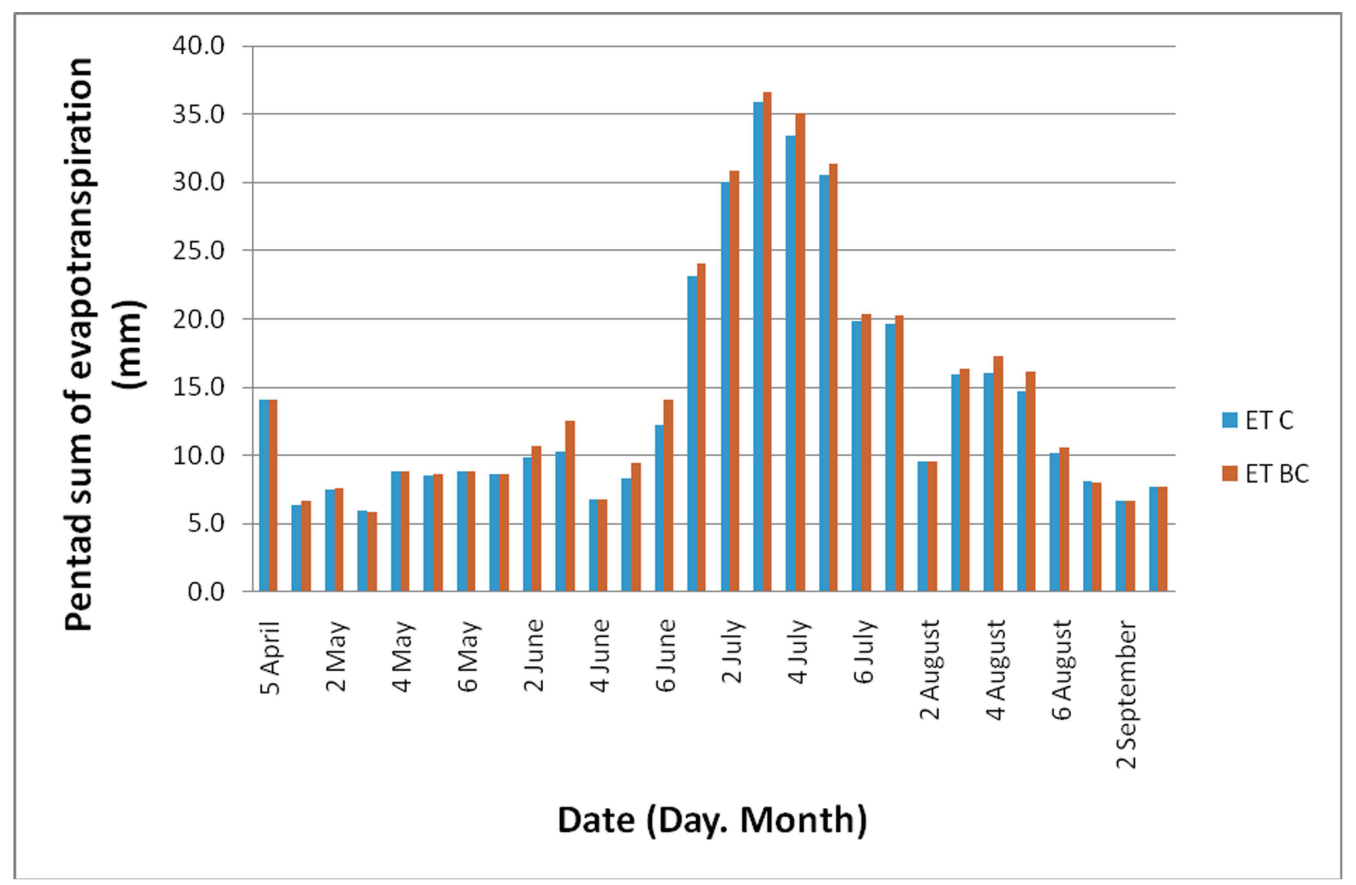

Figure 5. Five-day sums of evapotranspiration in the 2010 vegetation period

The evapotranspiration of plants polluted with $\mathrm{BC}$ was $4 \%$ greater than the control under the humid conditions in 2010, when there was no water deficit. The increase in evapotranspiration as a result of pollution is most pronounced in the middle of the vegetation period, when evapotranspiration consists mainly of transpiration. In 2010 this period coincided with very hot weather, which significantly increased the surface temperature of maize polluted with BC (Fig. 6).

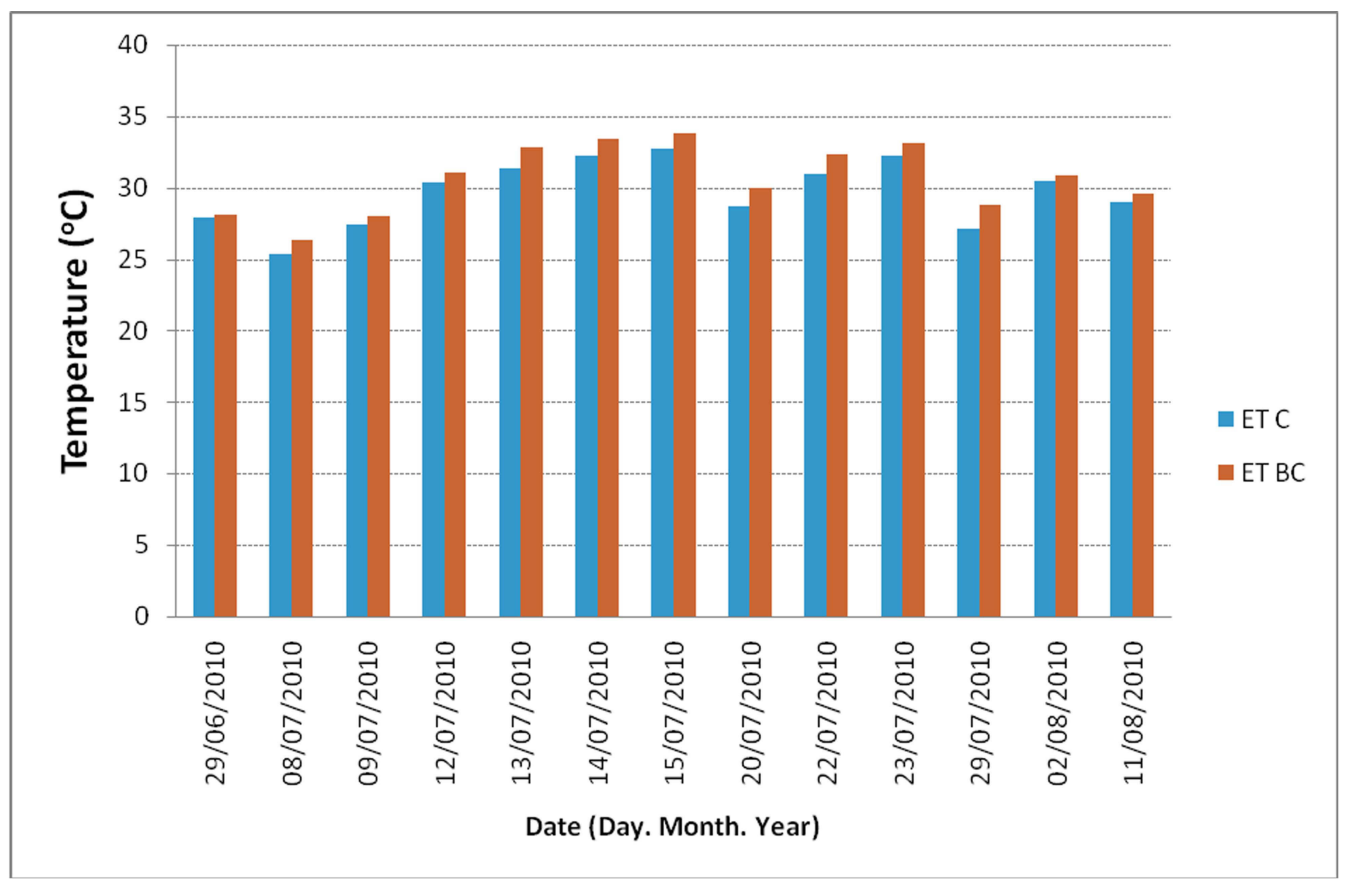

Figure 6. Canopy surface temperatures measured around solar noon, on clear days in 2010 
The canopy surface temperature rise, averaged over the vegetation cycle, was $0.9^{\circ} \mathrm{C}$ (significant at the 5\% level). The extent of warming was one and a half to two times the mean value on days with very high values of solar radiation. Maize treated with BC attempted to dissipate this absorbed energy surplus through enhanced evapotranspiration, for which the necessary water was available in this year due to the excessive rainfall and, in the ET treatment, from the continuous water supplies. There are gaps in the data for the first part of the vegetation period, as there were very few cloudless days with no rainfall or with a closed canopy when surface temperatures could be detected. From July to mid-August the only problem arising with the use of an infrared thermometer was that on occasion it was necessary to wait for a longer period to obtain comparable data pairs on a given sampling day. On windy, overcast days surface temperature measurements are unreliable. It was observed that if the 5-day evapotranspiration sum was less than $10 \mathrm{~mm}$, the pollution had little or no effect. This was true not only at the very beginning and end of the vegetation period, but also during cooler, wetter periods (e.g. 6-10 August in 2010).

When analysing the effect of soot pollution, consideration must be given to the fact that the 2010 vegetation period was wetter than usual. It rained on 83 of the 183 days of the 6-month maize vegetation period, i.e. 2.5-3 times more frequently than the longterm mean. The situation was no better for the short, 123-day vegetation period of the maize variety tested, when rainfall was recorded on 70 days. The humid nature of the 2010 season was consistent with the variable climate of the Carpathian Basin, though arid summers are much more frequent. While every third year is likely to be dry and hot, humid years can only be expected once a decade. A previous study (Anda, 1986) demonstrated that in drier summers the effect of cement pollution was much more pronounced, as found here for soot pollution in July.

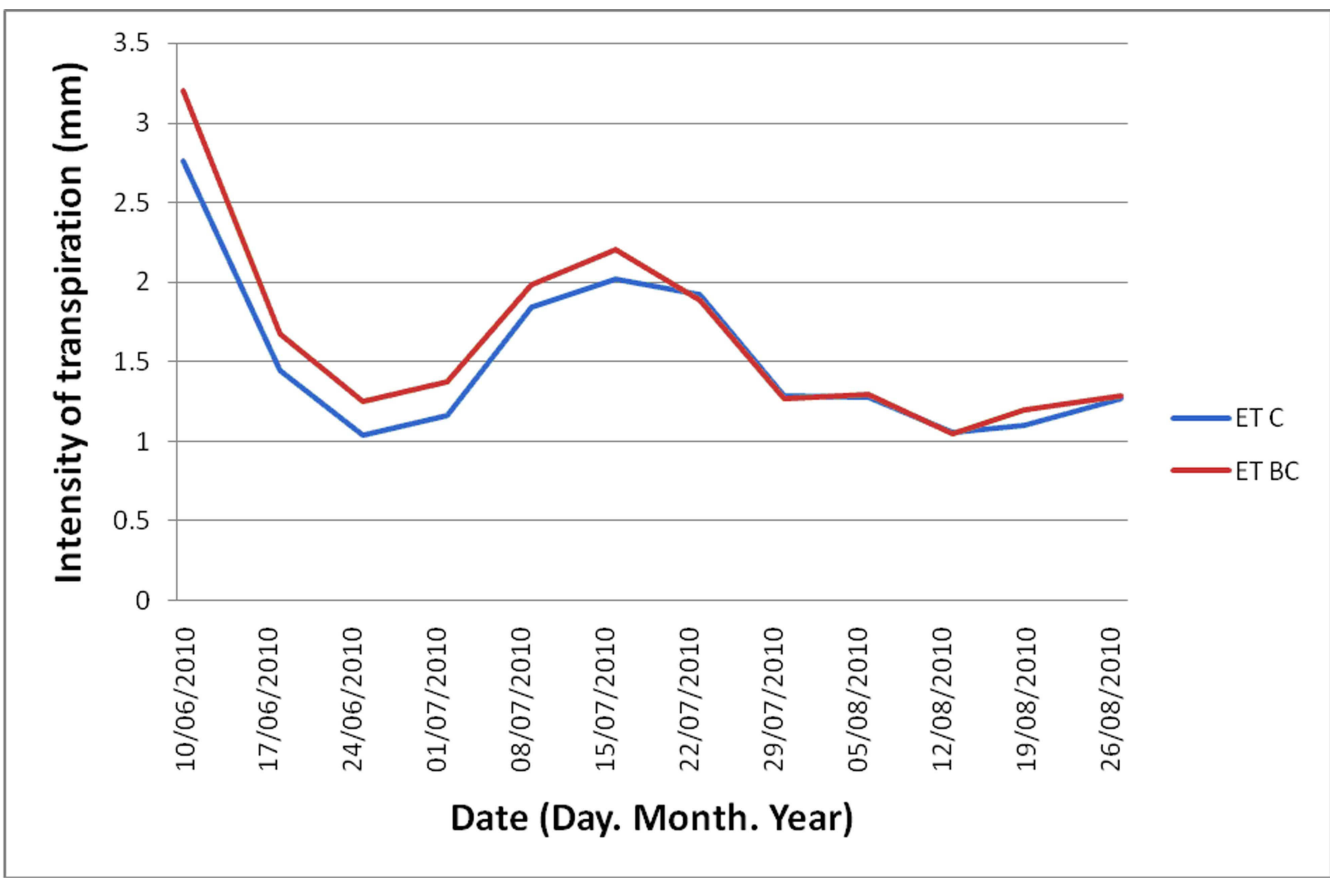

Figure 7. Intensity of transpiration per unit leaf area in polluted and control maize plants 
In soot-polluted plants, the transpiration per unit leaf area rose by $11.6 \%$ by the time maximum LAI was reached (Fig. 7). The enhancing effect of soot pollution on the intensity of transpiration could no longer be detected on the descending branch of the curve describing annual changes in the leaf area, i.e. during the period of leaf withering. In terms of the whole vegetation cycle, the polluted plants lost $7.2 \%$ more water per $\mathrm{m}^{2}$ assimilation area than the untreated control maize plants. The highest transpiration intensity was recorded before the canopy closed (on 10 June 2010), when the control and polluted plants had a daily water loss of 2.76 and $3.2 \mathrm{~mm}$ water per $\mathrm{m}^{2}$ leaf area, respectively.

\section{Dry matter production of maize}

No signification difference in total dry matter production could be detected in response to either water supplies or pollution, in accordance with the humid nature of the vegetation period (Table 2).

The most pronounced difference caused by supplementary water supplies was the $16.7 \%$ increase in stalk dry matter in ET plants compared with the rainfed plots (significant at the $0.1 \%$ level), confirming the enhancement of vegetative development in plants with better water supplies. The grain dry matter content was not significantly modified by supplementary irrigation, though there was a tendency for it to be higher in the rainfed plots. This could again be attributed to the unusual weather conditions in 2010, when the excessive rainfall and continuous water replacement saturated the soil in the ET tanks, leading on occasion to soil air deficiency, as also observed in a previous study (Anda, 1995).

Soot pollution caused an $8.8 \%$ reduction (significant at the 5\% level) in the total dry matter production of the rainfed plots. Neither TDM nor its distribution changed in the evapotranspirometer, so neither the stalk nor the grain dry matter exhibited a significant response to pollution. The soot had a tendency to reduce stalk dry matter, but this was not significant $(12.1 \%)$.

The harvest index was not modified by pollution on the rainfed plots $(0.49$ and 0.5$)$. In the ET treatment HI was 7-8\% lower than on the rainfed plots. The HI value of sootpolluted ET maize was $6.7 \%$ higher than that of the ET control (significant at the 5\% level).

One positive aspect of the ET treatment was the complete lack of deformed ears in the polluted variant. In contrast, there was a rise of $10.7 \%$ in the ratio of deformed ears on the BC-treated rainfed plots (significant at the 5\% level). 
Table 2. Changes in maize yields and total dry matter production in 2010. S: stalks, G: grain, TDM: total dry matter. *, **, ***: Differences significant at the 5, 1 and $0.1 \%$ levels, respectively. $n$ s: non-significant

\begin{tabular}{|c|c|c|c|}
\hline Variable & Mean & Standard Error & $\mathbf{P}>|\mathbf{t}|$ \\
\hline ET C S & 1.23 & 0.03 & 0.0000 \\
\hline ET BC S & 1.08 & 0.05 & 0.0003 \\
\hline Difference & $0.14^{\mathrm{ns}}$ & 0.06 & 0.0613 \\
\hline ET C G & 0.93 & 0.09 & 0.0092 \\
\hline ET BC G & 0.91 & 0.02 & 0.0005 \\
\hline Difference & $0.02^{\mathrm{ns}}$ & 0.09 & 0.8389 \\
\hline ET C TDM & 2.18 & 0.10 & 0.0022 \\
\hline ET BC TDM & 1.99 & 0.09 & 0.0021 \\
\hline Difference & $0.19^{\mathrm{ns}}$ & 0.14 & 0.2335 \\
\hline PCS & 1.04 & 0.02 & 0.0000 \\
\hline P BC S & 0.98 & 0.06 & 0.0001 \\
\hline Difference & $0.05^{\mathrm{ns}}$ & 0.06 & 0.4264 \\
\hline$P C G$ & 1.11 & 0.04 & 0.0001 \\
\hline P BC G & 0.98 & 0.03 & 0.0000 \\
\hline Difference & $0.13 *$ & 0.05 & 0.0423 \\
\hline P C TDM & 2.13 & 0.04 & 0.0000 \\
\hline P BC TDM & 1.95 & 0.05 & 0.0000 \\
\hline Difference & $0.18 *$ & 0.06 & 0.0266 \\
\hline ET C S & 1.23 & 0.03 & 0.0000 \\
\hline PCS & 1.04 & 0.02 & 0.0000 \\
\hline Difference & $0.19 * *$ & 0.04 & 0.0013 \\
\hline ET C G & 0.93 & 0.09 & 0.0092 \\
\hline P C G & 1.09 & 0.04 & 0.0000 \\
\hline Difference & $-0.16^{\mathrm{ns}}$ & 0.09 & 0.1188 \\
\hline ET BC S & 1.14 & 0.01 & 0.0001 \\
\hline P BC S & 0.94 & 0.04 & 0.0002 \\
\hline Difference & $0.20 * *$ & 0.05 & 0.0081 \\
\hline ET BC G & 0.91 & 0.02 & 0.0005 \\
\hline P BC G & 1.03 & 0.06 & 0.0000 \\
\hline Difference & $-0.122^{\mathrm{ns}}$ & 0.08 & 0.1571 \\
\hline ET C TDM & 2.18 & 0.10 & 0.0022 \\
\hline P C TDM & 2.13 & 0.04 & 0.0000 \\
\hline Difference & $0.05^{\mathrm{ns}}$ & 0.10 & 0.6306 \\
\hline ET BC TDM & 1.99 & 0.09 & 0.0021 \\
\hline P BC TDM & 1.95 & 0.05 & 0.0000 \\
\hline Difference & $0.04^{\mathrm{ns}}$ & 0.10 & 0.7163 \\
\hline
\end{tabular}




\section{Conclusions}

The geographical location of the Carpathian Basin is favourable for the development of extreme weather events. Despite the predictions that global warming would lead to drier weather, the 2010 vegetation period was of an extremely humid nature, with air temperatures near the long-term mean, but considerably more rainfall than usual.

Irrespective of pollution, the length of the period from sowing to full maturity was a week longer in the ET treatment, confirming earlier local observations that irrigation prolonged the vegetation period. Among the phenophases, only tasselling was delayed by a week in the ET treatment, due to the weather in July, the only month in the year that was $1.8^{\circ} \mathrm{C}$ warmer than average.

Neither the water supplies nor the soot pollution had any influence on the LAI from sowing to full maturity. There could be many explanations for the fact that soot pollution had no effect on LAI in 2010. The low rate applied, the plentiful rainfall supplies and the low value of LAI could all have contributed to the similarity in the leaf areas of the BC-treated and control maize. As stated by Grantz et al. (2003), the likelihood of foliar contact and the potential direct effects of particulate matter on vegetation increase with LAI.

There was a one-week delay in reaching maximum leaf area in the ET tanks, which could be attributed to the hot July. Since the soot caused changes in the withering of the foliage after full maturity, LAI measurements were continued until the last green leaf had disappeared. It was surprising to note that soot pollution delayed leaf withering irrespective of the water supplies. In the case of grain maize production, this would not influence the yield, as the delay occurred after full maturity. The cause was clearly the cool wet weather in late summer, when the greater radiation absorption resulting from the soot coating did not have a negative effect on the duration of the remaining leaves as there was little solar radiation.

The heat absorption of the soot increased the surface temperature of the maize plants, which attempted to dissipate the surplus energy through greater transpiration. Total annual evapotranspiration increased by $4 \%$, with the greatest rise in the hottest part of the vegetation period, particularly in July. The heat absorption of soot could be clearly traced in the evapotranspiration data even under the humid conditions of 2010, but this phenomenon only has a pronounced effect on plant energy intake in the case of intense irradiation. This is reflected in the fact that BC had little or no influence on water losses in periods with low evapotranspiration sums of 6-8 $\mathrm{mm} / 5$-day period. In years with more intense solar radiation soot may have a more pronounced effect on evapotranspiration, as witnessed during the hot period in July. The evapotranspiration recorded per unit leaf area for soot-polluted plants rose significantly up to maximum LAI, drawing attention to the greater sensitivity of younger leaves to pollution.

The humid nature of the year was confirmed by the fact that there was no significant difference in total dry matter production between the two water supply treatments. In both treatments, however, soot caused a reduction in TDM, though the difference was only significant $(8.8 \%)$ on the rainfed plots, suggesting that the soot caused less damage to the dry matter production of plants grown in ET plants than on non-irrigated plots. There was also no significant difference in the grain dry matter of maize in the ET treatment as the result of soot pollution, while on the rainfed plots a grain dry matter reduction of $12.4 \%$ was recorded (significant at the $5 \%$ level). It is worth noting that the stalk dry matter tended to decline to a greater extent than that of the grain $(12.1 \%$, 
non-significant). The decrease in stalk dry matter on the rainfed plots was only half that measured in the ET tanks, and was again non-significant.

Supplementary water supplies had a favourable effect on the vegetative growth of maize. In contrast with the rainfed plots, there was no significant change in the grain dry matter in polluted ET tanks, suggesting that the damaging effect of soot pollution can be mitigated by supplementary water supplies even in humid years.

It can be concluded from the results that the plant damage caused by "pure" soot, free of heavy metals, arises mainly due to the absorption of excess radiation, which is only manifested unambiguously in arid years with high levels of solar radiation. This is underlined by the surface temperatures and evapotranspiration data presented for July. On areas exposed to continuous low rates of soot pollution, irrigation could be an effective tool in moderating the effect on plants of air-borne $\mathrm{BC}$ pollution.

Acknowledgement. The financial and infrastructural support of the State of Hungary and the European Union in the frame of the TÁMOP-4.2.1/B-09/1/KONV-2010-0003 project is gratefully acknowledged.

\section{REFERENCES}

[1] Agarwal, T., Bucheli, T.D. (2011): Is black carbon a better predictor of polycyclic aromatic hydrocarbon distribution in soils than total organic carbon? - Environ. Pollution 159(1): 64-70.

[2] Anda, A. (1986): Effect of Cement Kiln Dust on the Radiation Balance and Yields of Plants. - Environ. Pollution A(40): 249-256.

[3] Anda, A. (1995): Problems in lysimeter use for determining the water demand of sugar beet. - Időjárás 99(1): 33-43.

[4] Borken, J., Steller, H., Meretei, T., Vanhove, F. (2007): Global and country inventory of road passenger and freight transportation: fuel consumption and emissions of air pollutants in the year 2000. - Transportation Research Records Journal of the Transportation Research Board: 127-136.

[5] Grantz, D.A., Garner, J.H.B., Johnson, D.W. (2003): Ecological effects of particulate matter. - Environment International 29: 213-239.

[6] Kuhlbusch, T.A.J., Crutzen, P.J. (1996): Black carbon, the global carbon cycle and atmospheric carbon dioxide. - In: Levine, J.S. (ed.) Biomass Burning and Global Change, MIT Press: 169.

[7] Lehmann, J., Sohi, S. (2008): Comment on "fire-derived charcoal causes loss of forest humus". - Science 321: 1295.

[8] Liang, B., Lehmann, J., Sohi, S.P., Thies, J.E., O’Neill, B., Trujillo, L., Gaunt, J., Solomon, D., Grossman, J., Neves, E.G., Luizão, F.J. (2010): Black carbon affects the cycling of non-black carbon in soil. - Organic Geochemistry 41(2): 206-213.

[9] Lorenz, K., Lal, R., Jiménez, J.J. (2010): Characterization of soil organic matter and black carbon in dry tropical forests of Costa Rica. - Geoderma 158: 315-321.

[10] Pietikäinen, J., Kiikkilä, O. Fritze, H. (2000): Charcoal as a habitat for microbes and its effects on the microbial community of the underlying humus. - Oikos 89: 231-242.

[11] Quénéa, K., Derenne, S., Rumpel, C., Rouzand, J.N., Gustaffson, O., Carcaillet, C., Mariotti, A. Largeau, C. (2006): Black carbon yields and types in forest and cultivated sandy soils (Landes de Gascogne, France) as determined with different methods: Influence of change in land use. - Organic Geochemistry 37(9): 1185-1189.

[12] Ramanathan V., Carmichael, G. (2008): Global and regional climate changes due to black carbon. - Nature Geoscience 1: 221-222. (http://www.sciencedaily.com/releases /2008/03/080323210225.htm) 
[13] Samaras, C., Meisterling, K. (2008): Life cycle assessment of greenhouse gas emissions from plug-in hybrid vehicles: implications for policy. - Environ. Science \& Technology 42: 3170-3176.

[14] Schmidt, M.W.I., Noack, A.G. (2000): Black carbon in soils and sediments: analysis, distribution, implications, and current challenges. - Global Biogeochemical Cycles 14: 777-793.

[15] Schmidt, M.W.I., Skjemstad, J.O., Czimczik, C.I., Glaser, B., Prentice, K.M., Gelinas, Y., Kuhlbusch, T.A.J. (2001): Comparative analysis of black carbon in soils. - Global Biogeochemical Cycles 15: 163-167.

[16] Smith, K.E.C., Jones, K.C. (2000): Particles and vegetables: implications for the transfer of particle-bound organic contaminants to vegetation. - Sci. Total Environ. 246: 207-36.

[17] Steiner, C., Teixeira, W.G., Lehmann, J., Zech, W. (2004): Microbial response to charcoal amendments of highly weathered soils and Amazonian Dark Earths in Central Amazonia - preliminary results, Amazonian Dark Earths: Explorations in Time and Space. - Springer, Berlin, Germany: 212.

[18] Taha, G., Box, G.P., Cohen, D.D., Stelcer, E. (2007): Black Carbon Measurement using Laser Integrating Plate Method. - Aerosol Science and Technology 41(3): 266-276. 